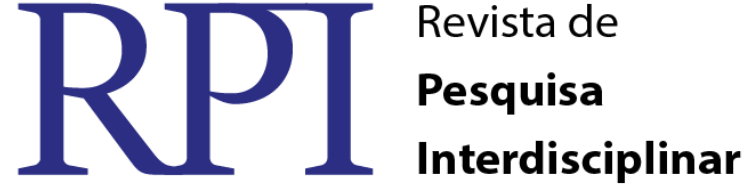

\section{ESTÁGIO SUPERVISIONADO: PRÁTICAS INOVADORAS NO ENSINO DE ESTATÍTICA E PROBABILIDADE NO ENSINO FUNDAMENTAL}

\author{
Fernanda Felipe de Lima - UFCG ${ }^{1}$ \\ Rosinângela Cavalcanti da Silva - UFCG ${ }^{2}$
}

\begin{abstract}
RESUMO
A educação matemática para o papel do educador é de grande responsabilidade, pois tem a missão de despertar no aluno o raciocínio lógico, instigar o pensamento independente, a criatividade e a capacidade de interpretar e solucionar problemas. A precisão de tornar o ensino da matemática atrativo e interessante faz-nos arquitetar práticas diferenciadas, ausentando-se das práticas tradicionais que não vem dando certo. Nesta perspectiva, o presente trabalho visa relatar a experiência vivenciada no Estágio Supervisionado, realizado em uma escola da rede municipal de ensino da cidade de Cajazeiras/PB, durante a disciplina Estágio Curricular Supervisionado II, exercido numa turma do $9^{\circ}$ ano do Ensino Fundamental. Neste trabalho é evidenciado a importância do estágio na formação docente, bem como a aplicação de atividades diversificadas no ensino da matemática tornando-se uma ferramenta importantíssima para o estímulo da aprendizagem dos alunos, tais recursos inovadores desmistificam que a disciplina é para poucos, o que a maioria dos alunos pensam e imaginam antes mesmo de se permitir conhecer a matemática. Portanto, saindo do método tradicional, os alunos veem e praticam uma matemática em que todos são capazes de aprender e gostar. Este artigo descreve as atividades desenvolvidas no componente curricular Estágio Supervisionado II, tais como as observações realizadas nas aulas do professor da turma e a regência, realizado no período 2015.2. Apontando, dessa forma, que a experiência adquirida durante essa atividade curricular se demonstra imprescindível ao discente, uma vez que o alinhamento do conhecimento obtido na academia com essa experiência vivenciada no ambiente escolar torna-o verdadeiramente capacitado para a vida profissional. Serão relatadas as observações das aprendizagens dos alunos através da contextualização do conteúdo de Estatística por meio da História da Matemática, pesquisa em sala de aula, construção de maquetes e a aplicação de jogos no ensino de Probabilidade.
\end{abstract}

Palavras- chave: Estágio; Atividades diferenciadas; Estatística e Probabilidade.

\section{SUPERVISED STAGE: INNOVATIVE PRACTICES IN TEACHING STATISTICS AND PROBABILITY IN FUNDAMENTAL TEACHING}

\begin{abstract}
Mathematics education for the role of the educator is of great responsibility, because it has the mission of awakening the students logical reasoning, instigate independent thinking, creativity and the ability to interpret and solve problems. The accuracy of making teaching attractive and interesting math makes us devise different practices, absent from traditional practices that do not see working. In this perspective, this paper describes the experience lived in supervised training, held in a school municipal schools in the city of Cajazeiras / PB, during the Supervised II discipline exercised in a class of 9th grade of elementary school. This work shows the importance of training in teacher training, and the implementation of diverse activities in teaching mathematics becoming a very important tool for the encouragement of student learning such innovative features demystify that
\end{abstract}

\footnotetext{
${ }^{1}$ Universidade Federal de Campina Grande - limafernanda.lg@gmail.com

${ }^{2}$ Universidade Federal de Campina Grande -rosinangela_sjp@ hotmail.com
} 
discipline is for the few, which most students think and think before even possible to know the math. Therefore, leaving the traditional method, students see and practice in mathematics that everyone can learn and enjoy. This article describes the activities in the curriculum component Supervised II, such as the observations made during the stage and conducting stage, carried out 2015.2. Pointing thus the experience gained during this curricular activity demonstrates essential to students, since the alignment of the knowledge gained at the gym with this experience lived in the school environment makes it truly capable of working life. the observations of student learning will be reported through the contextualization of Statistical content through the History of Mathematics, research in the classroom, building models and the application of games in teaching probability.

Keywords: Internship; different activities; Statistics and probability.

\section{INTRODUÇÃO}

O estágio detém missão fulcral na construção do arcabouço curricular do futuro docente, pois proporciona ao acadêmico o contato direto com os agentes envolvidos no processo ensino-aprendizagem. Possibilita, com isso, o aperfeiçoamento do licenciando em suas atividades (dentro e fora) da sala de aula. Além disso, oportuniza ainda a observação da prática pedagógica dos professores aguçando a percepção para empregar novas práticas que possam auxiliar no ensino-aprendizagem da matemática. Portanto, a experiência adquirida durante essa atividade curricular demonstra-se imprescindível ao discente, uma vez que o alinhamento do conhecimento obtido na academia com essa experiência vivenciada no ambiente escolar permite colocar em prática as teorias estudadas e torna a escola um ambiente de estudo, preparando o futuro professor para sua prática docente.

Diante de observações anteriores a regência em sala de aula, foi detectada as carências e deficiências da turma na disciplina de Matemática, a partir dessa análise, foi elaborado um projeto com o objetivo de apresentar uma proposta didática de caráter prático para aprendizagem significativa de conceitos de Estatística e Probabilidade, como também, priorizar a participação dos alunos na construção do conhecimento, por meio de uma metodologia que favorecesse atividades diferenciadas.

O projeto "Estatística e Probabilidade no Ensino Fundamental" teve como intenção apresentar o conteúdo de Estatística e Probabilidade em um contexto diferenciado através de atividades práticas que vão além do método tradicional de ensino, com a finalidade de promover a compreensão do conteúdo para o ensino e aprendizagem, aplicando uma sequência didática que envolva a realização de pesquisas, o estudo da História da Matemática,

RPI Revista de Pesquisa Interdisciplinar, Cajazeiras, v. 1, Ed. Especial, 249 - 258, set/dez. de 2016. 
jogos, resolução de situações problema e atividades de pesquisa, de maneira a favorecer modelos mais dinâmicos e caracterizados por novas metodologias de ensino.

As atividades propostas foram utilizadas como instrumentos para o ensino dos conhecimentos básicos de Estatística e Probabilidade, considerando e abordando os conteúdos propostos pelos Parâmetros Curriculares Nacionais (1998), como: capacidade de leitura, interpretação e organização de dados; construção de tabelas e gráficos; concepção e compreensão de: espaço amostral, média, moda e mediana; o cálculo da probabilidade de um evento por uma razão; frequência absoluta e relativa. Com a intenção de que os alunos sejam capazes de fazer uso de estratégias de resolução de problemas; interpretação de textos relacionados ao conteúdo; e através de trabalho de pesquisa em grupo, favorecer a comunicação e interação entre os mesmos, bem como a oportunidade de aplicar os conhecimentos adquiridos por meios de jogos desenvolvendo o raciocínio lógico, causando melhoramento e aprimoramento no aprendizado.

Mediante a aplicação dessas atividades é possível verificar o quão importante é a prática inovadora de ensino, pois durante todo o estágio, os discentes foram participativos e mostraram interesse de modo que não seria demonstrado se as aulas tivessem sido ministradas como até então estavam acostumados. Até mesmo o professor da turma deixou claro que a metodologia desenvolvida foi essencial para despertar o interesse dos alunos. A experiência foi satisfatória tanto para os discentes, pois possibilitou maior aproximação ao ensino da matemática, como de grande relevância como futuro profissional, pois o experimento permite vivenciar a realidade do profissional e desse modo cogitar e planejar uma maneira para fazer um trabalho eficaz.

\section{Referencial Teórico}

A disciplina de Matemática no ambiente escolar é tida como um desafio de ensino para todas as séries escolares, pois o índice de reprovação é maior do que em outras disciplinas, como também é dita a mais difícil pela maioria dos alunos. Um dos grandes desafios para superar e melhorar esse quadro, é buscar e aplicar estratégias que tornem o ensino da matemática agradável e acessível aos alunos de maneira mais clara e compreensível, que gere nos discentes o gosto pela disciplina. 
Segundo (SEIBERT 2005), a educação deve ter objetivos mais amplos do que o mero saber técnico, que é a compreensão do mundo e a formação de cidadãos plenos. Para alcançar esses objetivos é preciso, acima de tudo, querer mudar e acreditar que existe outra forma de ensinar que não seja só transmitir conteúdo.

A aprendizagem significativa vai além de decorar fórmulas e reproduzir atividades duramente; o aprendizado, para que propicie ao aluno uma formação de cidadão crítico, necessita que seja fornecido oportunidades no ambiente escolar que exercite no aluno a interação do indivíduo com suas habilidades, autoconhecimento, capacidade de comunicação, pois é na prática que diagnosticamos as dificuldades, e para que isso ocorra é imprescindível atividades diversificadas, diferentes da forma tradicional.

A Estatística e a Probabilidade fazem parte do currículo de Matemática do Ensino Fundamental II, embora seja pouco trabalhado nessas séries de ensino. Esse conteúdo é considerado de grande importância na formação dos alunos, pois dentre tantos outros conteúdos de matemática, este está presente no dia a dia dos discente. Portanto, tal aprendizagem contribui amplamente para o desenvolvimento de uma educação matemática crítica.

Daí a preocupação de passar esse conteúdo na série final do Ensino Fundamental, permitindo que alunos adquirem informações básicas de Estatística e Probabilidade, de forma que propicie sua formação escolar. Lopes (2008) aponta que o estudo do ensino da Estatística e da Probabilidade na Educação Básica torna-se indispensável ao cidadão nos dias de hoje e em tempos futuros, delegando ao ensino da matemática o compromisso de não só ensinar o domínio dos números, mas também a organização de dados, leitura de gráficos e análises estatísticas.

É por meio disso que o ensino de estatística deve ser abordado de forma que leve em conta os interesses dos estudantes, utilizando-se de material de diversas fontes da mídia e propondo que eles realizem suas próprias pesquisas, trabalhando no aluno, dessa forma, a capacidade de coletar e organizar dados e, diante disso, construir gráficos gerando competências de posteriormente fazer leitura de outros gráficos presentes ao longo dos estudos.

Acreditamos que é necessário desenvolver uma prática pedagógica na qual sejam propostas situações em que os estudantes realizem atividades, as quais considerem seus contextos e possam observar e construir os eventos

RPI Revista de Pesquisa Interdisciplinar, Cajazeiras, v. 1, Ed. Especial, 249 - 258, set/dez. de 2016. 
possíveis, por meio de experimentação concreta, de coleta e de organização de dados. (LOPES, 2008, P. 58)

Assim, é importante explorar a pesquisa, a busca de informação, para construir o conhecimento na coleta e organização de dados representando-os através de tabelas, gráficos e maquetes, sendo uma ferramenta precisa no ensino de Estatística. Pois o conhecimento estatístico requer de leitura e interpretação de informações veiculadas pela mídia através de dados estatísticos; em que esses dados são representados através de gráficos e tabelas.

Atividades diferenciadas geram aprendizagem e interesse no aluno, um desses recursos é a História da Matemática, importante para aplicações de conteúdos da matemática. Mostrar para os alunos a História da Matemática relacionado ao conteúdo estudado é formidável, pois o aluno percebe a importância do estudo matemático ao longo de toda a existência e que não são apenas cálculos feitos, e sim, que os cálculos que eles aprendem tem utilidade em toda a vida, está presente em todo o meio que os cercam. Segundo Brito e Miorim (1999), a partir da aquisição de conhecimentos históricos e filosóficos dos conceitos matemáticos, o professor tem a possibilidade de diversificar suas técnicas pedagógicas e tornar-se mais criativo na elaboração de suas aulas, as quais podem provocar o interesse dos alunos para o estudo da matemática.

D’Ambrosio (1999) argumenta que uma abordagem adequada para incorporar a História da Matemática na prática pedagógica deve enfatizar os aspectos socioeconômicos, políticos e culturais que propiciaram a criação matemática.

A História da Matemática é importante para revelar de forma mais clara a importância desse estudo em nossas vidas, mostrando a eficiência e utilidade nas situações do dia a dia, motivando assim os alunos. Fossa (2001) relata que a História da Matemática é uma das formas de se contextualizar o ensino da Matemática escolarizada como possibilidades de situar o conhecimento no tempo e no espaço bem como motivar os alunos para um despertar para a aprendizagem da Matemática.

Um outro recurso para tornar as aulas de Estatística e Probabilidades mais significativa é a resolução de situações problemas, contextualizadas com assuntos do dia a dia dos alunos, uma vez que provocam um interesse maior e participação na resolução dos problemas.

RPI Revista de Pesquisa Interdisciplinar, Cajazeiras, v. 1, Ed. Especial, 249 - 258, set/dez. de 2016. 
"Não é mais possível apresentar a Matemática aos alunos de forma descontextualizada, sem levar em conta que a origem e o fim da Matemática é responder às demandas de situações-problema da vida diária.” (GROENWALD, FILLIPSEN, 2002).

Através de um ensino contextualizado, o discente compreende o porquê de estudar determinado conteúdo, e dessa forma surge o interesse e a vontade de aprender aquilo que considera útil e eficiente em sua vida. Segundo D’Ambrósio:

Contextualizar a Matemática é essencial para todos. Afinal, como deixar de relacionar os Elementos de Euclides com o panorama cultural da Grécia Antiga? Ou a adoção da numeração indo-arábica na Europa como florescimento do mercantilismo nos séculos XIV e XV? E não se pode entender Newton descontextualizado. (...) Alguns dirão que a contextualização não é importante, que o importante é reconhecer a Matemática como a manifestação mais nobre do pensamento e da inteligência humana... e assim justificam sua importância nos currículos (D’AMBROSIO, 2001).

O ensino da Matemática na série final do Ensino Fundamental II deve levar em consideração a importância de um adequado desenvolvimento do pensamento matemático, privilegiando a compreensão e o desenvolvimento de habilidades e competências, preparando os educandos para uma nova etapa escolar, o Ensino Médio.

É fundamental inserir as crianças em atividades que permitam um caminho que vai da imaginação à abstração, através de processos de levantamento de hipóteses e testagem de conjecturas, reflexão, análise, síntese e criação, pela criança, de estratégias diversificadas de resolução dos problemas em jogo. (GRANDO, 2000, p.20).

Segundo Grando (2000) a resolução de problemas e as atividades de jogos estão relacionadas quando, ao observarmos o comportamento de uma criança em situações de brincadeiras e/ou jogo, percebe-se o quanto ela desenvolve sua capacidade de fazer perguntas, buscar diferentes soluções, repensar situações avaliar atitudes, encontrar e reestruturar novas relações, ou seja, resolver problemas.

Os jogos apresentam os benefícios de aproximar o educador da turma, facilitando a comunicação, e desse modo, o educador consegue diagnosticar as dificuldades surgidas no decorrer do jogo, pois a todo instante os alunos fazem uso de estratégias de resolução em que por meio disso utilizam dos conhecimentos adquiridos do conteúdo apresentado no jogo. 
Para Grando (1995), o jogo representa uma situação-problema simulada e determinada por regras, em que o indivíduo busca, a todo o momento, elaborando estratégias e reestruturando-as, vencer o jogo, ou seja, resolver o problema. Este dinamismo característico do jogo é o que possibilita identificá-lo no contexto da resolução de problemas.

Segundo Borin (1996, p.9) outro motivo para a introdução de jogos nas aulas de matemática é a possibilidade de diminuir bloqueios apresentados por muitos de nossos alunos que temem a matemática e sentem-se incapacitados para aprendê-la. Dentro da situação de jogo, onde é impossível uma atitude passiva e a motivação é grande, notamos que, ao mesmo tempo em que estes alunos falam da matemática, apresentam também um melhor desempenho e atitudes mais positivas frente a seus processos de aprendizagem.

Tais pressupostos teóricos fundamentam a concepção de um processo de ensino e aprendizagem construtivista, empregando recursos didáticos diferenciados em sala de aula e proporcionando um ambiente para o qual gere aprendizagem significativa. Revelando a importância de atividades práticas, a utilização da História da Matemática, estudo de situações problemas e jogos no processo ensino-aprendizagem, almejando a motivação dos alunos e o desenvolvimento de habilidades competências na construção do conhecimento.

\section{Metodologia}

Este trabalho foi desenvolvido numa turma do $9^{\circ}$ ano do Ensino Fundamental no período de cinco semanas. Os conteúdos foram trabalhados de forma dinâmica e diferenciada. Tais estudos foram feitos através de atividades práticas, pesquisas, construção de gráficos e maquetes, como também jogos e situações problemas, sempre iniciando através de situações práticas permitindo a avaliação dos conhecimentos prévios dos discentes sobre o assunto exposto, explorando a interpretação, para que os mesmos construíssem os conceitos dos conteúdos abordados.

Inicialmente, foi feito o estudo do conteúdo de Estatística. Foram feitas breves considerações sobre a História da Estatística, explicando a importância de estudarmos a História da Matemática, mostrando sua necessidade e utilidade nos dias atuais, identificando assim algumas aplicabilidades da estatística em áreas no nosso cotidiano. Os alunos também trabalharam com pesquisas em revistas, com o objetivo de proporcionar aos discentes o contato com materiais que trazem dados estatísticos. Foi aplicado um questionário com o RPI Revista de Pesquisa Interdisciplinar, Cajazeiras, v. 1, Ed. Especial, 249 - 258, set/dez. de 2016. 
objetivo de diagnosticar os conhecimentos prévios dos alunos. Em seguida, foi feita uma pesquisa em sala de aula sobre a estatura dos alunos, com a utilização de trena e representado no quadro, estudando assim, o conceito de censo, amostra, variável quantitativa e variável qualitativa.

Em outros momentos, aconteceram pesquisas sobre diversos assuntos dentro da sala de aula, gerando interesse e adquirindo a participação de todos; paralelamente ao estudo de situações problemas durante a exposição dos conteúdos. Encerrando o estudo de Estatística, foi proposto uma atividade em grupo de pesquisa na escola, sendo apresentados temas relacionados a música, internet e esporte. Os alunos apresentaram suas coletas de dados e relataram como procedeu a pesquisa e transcreveram os dados coletados para tabelas e em seguida construíram o gráfico da pesquisa em seus cadernos. Em seguida, os discentes receberam materiais concretos para a construção de maquetes, que foram fixadas nas paredes da sala de aula, oportunizando os alunos divulgarem seus trabalhos e apresentarem aos colegas de outras turmas.

O conteúdo de Probabilidade foi iniciado com atividades em duplas, as quais apresentavam uma breve história dos jogos de azar, situações nas quais os alunos precisaram dialogar e usar a intuição trabalhando algumas discussões sobre sorte, aleatoriedade e noções de Probabilidade. E jogos, que levaram o aluno a pensar e construir estratégias de resolução, tais como o jogo "Cara ou Coroa", utilizando moedas, e o "Jogo do produto", utilizando dados e registrando em tabelas. Assim foram realizados experimentos com material concreto tornando a aula mais atraente e participativa.

\section{Considerações Finais}

O Estágio foi uma experiência gratificante e prazerosa, componente importante e complementar na vida acadêmica do licenciando, sendo de grande relevância como futuro profissional. Oportunizou conhecer o ambiente escolar, colocando em prática os conhecimentos teóricos estudados nas disciplinas referentes. Durante o Estágio é possível vivenciar a realidade do profissional e desse modo planejar, estar e analisar maneiras para fazer um trabalho eficaz.

Ensinar Matemática é um grande desafio, vistos desde a escolha metodológica até a forma de aplicá-la com a devida preocupação em aflorar o interesse do aluno. Assim, surge a RPI Revista de Pesquisa Interdisciplinar, Cajazeiras, v. 1, Ed. Especial, 249 - 258, set/dez. de 2016. 
busca por estratégias que melhorem o ensino da Matemática em sala de aula, fazendo uma mudança no método trabalhado que não está tendo o resultado favorável à aprendizagem.

Dessa forma, diante das observações realizadas, foi elaborado um projeto para desenvolver uma metodologia diferenciada com objetivo principal de gerar aprendizagem significativa, fazendo com que o aluno seja o sujeito no seu processo de aprendizagem. Diante disso, foi permitido perceber que novas metodologias de ensino devem ser adotadas com base na necessidade de cada turma.

Entre as diversas possibilidades de trabalho para amenizar as dificuldades de aprendizagens escolares destaca-se a pesquisa feita através de situações práticas do dia-a-dia do aluno, a interpretação e resolução de situações problemas, bem como o estudo de gráficos e os jogos educativos; tais recursos didático de atividades diferenciadas devem ser utilizados como suporte na colaboração de uma prática mais dinâmica, significativa, oferecendo meios para o educando adquirir sua própria capacidade de desenvolver e interpretar conhecimentos matemáticos. Trabalhando desse modo, o estágio trouxe ao estagiário uma realização por ter atingido as expectativas esperadas em relação à aprendizagem dos alunos e a sua formação docente de modo eficiente, prático, discursivo e inovador.

\section{REFERÊNCIAS}

BORIN, J. Jogos e resolução de problemas: uma estratégia para as aulas de matemática. São Paulo: IME-USP, 1996.

BRASIL. (1998). Secretaria de Educação Fundamental. Parâmetros curriculares nacionais: Matemática/Secretaria de Educação Fundamental. MEC / SEF, Brasília.

BRITO, A. J.; MIORIM, M.A. A história na formação de professores de matemática: reflexões sobre uma experiência. Anais do III Seminário Nacional de História da Matemática, 1999.

D’AMBROSIO, U. A História da Matemática - Questões historiográficas e políticas e reflexos na Educação Matemática. In: BICUDO, M. A. V. (org.) Pesquisa em Educação Matemática: Concepções \& Perspectivas. São Paulo: UNESP, 1999, p.97-115.

D’AMBROSIO, Ubiratam. Educação Matemática: da teoria à prática. Campinas, Papirus, 2001 (Coleção Perspectiva em Educação Matemática).

FOSSA, Jonh A. Ensaios sobre a Educação Matemática. Belém: EDUEPA, 2001.

GRANDO, R. C. (1995). O Jogo e suas Possibilidades Metodológicas no Processo Ensino Aprendizagem da Matemática. Dissertação de Mestrado em Educação - UNICAMP, Campinas.

RPI Revista de Pesquisa Interdisciplinar, Cajazeiras, v. 1, Ed. Especial, 249 - 258, set/dez. de 2016. 
(2000). O conhecimento matemático e o uso de jogos na sala de aula. Campinas, SP. Tese de Doutorado. Faculdade de Educação, UNICAMP.

GROENWALD, Cláudia L. Oliveira e FILIPPSEN, Rosane Maria Jardim. O meio ambiente e a sala de aula. Educação Matemática em Revista. (SBME), n.13, p36-40, 2003.

LOPES, Celi Espasandin. (2008). O ensino da estatística e da probabilidade na educação básica e a formação dos professores. Caderno Cedes, Campinas, 28(74), 57-73.

O Ensino de Estatística e da Probabilidade na Educação Básica e a Formação de Professores. Cad. Cedes, Campinas, vol. 28, n. 74, p. 57-73, jan./abr. 2008. Disponível em: < http://www.scielo.br/pdf/ccedes/v28n74/v28n74a05.pdf > Acesso em: 27 mar. 2016.

SEIBERT, Tania Elisa. Matemática e educação ambiental: uma proposta com projetos de trabalho no ensino fundamental. Canoas: ULBRA, 2005. Dissertação de Mestrado. Universidade Luterana do Brasil, 2005. 